\title{
Urban tourism and population change: Gentrification in the age of mobilities
}

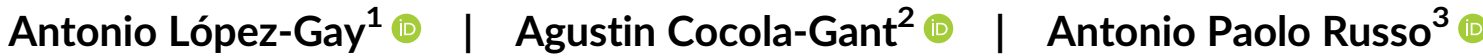

${ }^{1}$ Department of Geography, Universitat Autònoma de Barcelona and Centre d'Estudis Demogràfics, Barcelona, Spain

${ }^{2}$ Centre of Geographical Studies, Universidade de Lisboa, Lisbon, Portugal

${ }^{3}$ Department of Geography, Research Group 'Territorial Analysis and Tourism Studies' (GRATET), Universitat Rovira i Virgili,

Tarragona, Spain

Correspondence

Antonio López-Gay, Department of

Geography, Universitat Autònoma de

Barcelona and Centre d'Estudis Demogràfics,

Barcelona Spain.

Email: tlopez@ced.uab.es

\section{Funding information}

CERCA Programme/Generalitat de Catalunya; Department of Research and Universities, Generalitat de Catalunya, Grant/Award Number: 2017SGR22; EQUALIZED, European Research Council, Grant/Award Number: ERC2014-StG-637768; GLOBFAM, Ministerio de Ciencia, Innovación y Universidad (es), Grant/ Award Number: RTI2018-096730-B-I00; MOVIPOL, Ministerio de Economía y Competitividad, Grant/Award Number: CSO2014-60967-JIN; POLITUR, Ministerio de Economía, Industria y Competitividad, Grant/ Award Number: CSO2017-82156-R; SMARTOUR, Portuguese Science and Technology Research Council, Grant/Award Numbers: PTDC/GESURB/30551/2017, UIDB/00295/2020, UIDP/00295/2020;

Talent Research Program, Universitat Autònoma de Barcelona

\begin{abstract}
The prepandemic unbridled growth of tourism has triggered a significant debate regarding the future of cities; several authors suggest that neighbourhood change produced by tourism should be conceived as a form of gentrification. Yet research on population shifts-a fundamental dimension of gentrification-in such neighbourhoods is scarce. Our exploration of the Gòtic area in Barcelona, using quantitative and qualitative techniques, reveals a process of population restructuring characterised by a decrease of long-term residents and inhabited dwellings, and the arrival of young and transnational gentrifiers that are increasingly mobile and form a transient population. We then use some insights from the mobilities literature to make sense of these results. In the gentrification of the Gottic, the attractiveness of the area for visitors and for a wider palette of transnational dwellers feeds one another, resulting in an uneven negotiation whereby more wealthy and 'footloose' individuals gain access and control of space and housing over less mobile and more dependent populations.
\end{abstract}

\section{KEYWORDS}

Barcelona, gentrification, lifestyle migration, mobilities, population change, tourism, transnational gentrifiers

\section{1 | INTRODUCTION}

Ever since the seminal article by Elizabeth Becker (2015), the international media has given substantial coverage to the excesses of tourism and their effects, especially in larger European cities and in some established destinations. Debate on 'overtourism' and rising 'anti-tourism' stances has been assessed in analytic and critical ways (Butler \& Dodds, 2019; Colomb \& Novy, 2016; Koens, Postma, \& Papp, 2018; Milano, Cheer, \& Novelli, 2019), therefore revamping the scholarly interest for social change in cities, with a new focus on the agency of tourism. In fact, one of the most remarkable features of the relentless growth of tourism activity in cities, at least until the COVID-19 pandemic, is the impacts this is having on local communities. These include the externalities noted by early studies of tourism development such as the rising cost of commodities and housing, occupation of public space, noise and air pollution, among others. These impacts portend the exclusion and marginalisation of the most vulnerable collectives, as places are increasingly 'tuned' to the practices and affordabilities of visitors. 
Against this background, there is an increased interest in linking tourism with the restructuring of social geographies, suggesting that it drives gentrification (Cocola-Gant, 2018; García-Herrera, Smith, \& Mejías-Vera, 2007; Gotham, 2005; Gravari-Barbas \& Guinand, 2017; Janoschka, Sequera, \& Salinas, 2014; Wachsmuth \& Weisler, 2018). These authors focus on the role of the visitor economy (and in particular of the short-term hospitality platforms like Airbnb) and on processes of capital investment in widening rent gaps and causing the displacement of longstanding residents (Cocola-Gant \& Gago, 2019; García-Herrera et al., 2007; Gotham, 2005; Mendes, 2018; Wachsmuth \& Weisler, 2018; Yrigoy, 2019).

Despite the different forms, geographies and temporalities of the process, gentrification is by definition a process of population restructuring characterised by the displacement of existing populations and the arrival of newcomers with higher socio-economic status (Smith, 2002). In this sense, other authors note that the recent dynamics of tourist cities can hardly be framed as gentrification and suggest using the term touristification as a more accurate characterisation (Jover \& Díaz-Parra, 2019; Sequera \& Nofre, 2018 and 2019). These authors argue that tourism does cause the displacement of longstanding residents, but not social class upgrading, in the sense that an excessive growth of tourism is somehow incompatible with residential uses, and therefore, middle-class residents would not move into these areas. However, there is little empirical evidence to support this claim and to conclude what the tourism-led population restructuring of certain neighbourhoods looks like.

The aim of this paper is to fill this knowledge gap, which is conceptual, methodological and empirical. We do so through a case study of Barcelona, focusing on some of its neighbourhoods and in particular the Barri Gòtic (Gothic Quarter), possibly its core tourist attraction area. On the one hand, we pin down the sociodemographic patterns that characterise population restructuring at a neighbourhood level; on the other hand, we offer an interpretation of the observed attraction and displacement processes drawing from recent advances in the study of urban geography derived from the 'mobilities turn'. Our argument is that we need to move from the implicitly assumed distinction between residents and visitors to consider instead how the population restructuring of central areas in contemporary cities could be the result of an assemblage of emerging forms of temporary dwelling, among which tourism is a powerful driver. This paper further explores how transient mobile gentrifiers outcompete less mobile and more place-dependent populations in a negotiation over urban assets, ultimately leading to a process of population restructuring in which a local 'sedentary' population is replaced by floating transnational dwellers. Eventually, our objective is to characterise tourism-led gentrification as a particular process of population change, in which the question of population mobility plays a key role beyond the usual class dimension, and to present a framework of analysis that may be useful to confront other cases.

The structure of the paper is as follows. In the next section, we propose a discussion of how tourism may be linked to or induce certain socio-demographic dynamics at an area level, which we frame as peculiar avenues of gentrification. In the third section, we introduce our methodology and research design, based on a mixed-method approach with a fundamental focus on demographic data, complemented by in-depth interviews with residents offering further insights, which help to interpret the findings from the demographic analysis. We also contextualise our research in the Barri Gòtic of Barcelona, an area significantly impacted by tourism, which features the highest rate of tourist beds per inhabitant across the city. In the fourth section, we illustrate our empirical findings, exploring population changes in the Barri Gòtic since the late 1990s to 2017 and comparing them with other gentrified neighbourhoods in Barcelona that do not experience comparable tourism-related pressures. Interviews further reveal why the agency of tourism mobilities is central to understanding the differences between these neighbourhoods. Finally, in the fifth section, we conclude with an interpretation of such results suggesting that the 'mobilities turn' may contribute to understanding population restructuring in tourist areas.

\section{2 | GENTRIFICATION, TOURISM AND POPULATION CHANGE: INSIGHTS FROM THE MOBILITIES TURN}

Inherent to any definition of gentrification is a process of sociodemographic change and population restructuring (Smith, 2002). In the classical accounts of this process, gentrification hints at the displacement of a low-income population-particularly the elderly and those involved in manual labour-by young adults with higher levels of education and income and who are typically employed in managerial or professional services (Atkinson, 2000; Lees, Slater, \& Wyly, 2008; Smith, 2002; Van Criekingen, 2010). Gentrification is then characterised essentially as a process of socio-spatial change in which working-class residents are displaced by middle-class newcomers, generally resulting in an increase of the acquisitive and educational attainment level of the area's residents. Socio-demographic analyses have been used extensively to explore whether a place experiences gentrification. The most popular metrics trace changes in socio-economic status for census tracts through time (Atkinson, 2000; Hochstenbach, Musterd, \& Teernstra, 2015; Reese, DeVerteuil, \& Thach, 2010). To explain this change, gentrification studies have notably focused on residential mobility patterns and migration, analysing the profiles of in-movers and out-movers. Other authors argue that residential mobility is insufficient to explain social economic change at the neighbourhood level and that demographic shifts should be considered as well (see Hochstenbach \& van Gent, 2015, for an overview). For instance, because of the ageing of the traditional working class, change may result from high death rates of the long-term residents that are replaced by younger cohorts who are usually better educated than previous generations (for a critique of the displacement/replacement dichotomy, see Slater, 2009). Either way, in terms of age, the initial steps of gentrification imply a rejuvenation of the area concerned, as newcomers tend to be young adults, whereas elderly residents comprise a significant proportion of the out-mover population (Atkinson, 2000). In an analysis of how diverse age groups 
are involved in different forms of gentrification according to their life course transitions, Hochstenbach and Boterman (2018) contest the traditional view that gentrification is associated with the residential trajectories of young middle-class people as a transitory period in their life course, according to which gentrifiers would tend to move out of areas offering 'urban amenities'-such as street life, night-time recreation, global eateries and the like-when they settle down and have children. Instead, their research shows that many gentrifiers 'stay urban' after having children and also point to increasing numbers of elderly gentrifiers because of the ageing of affluent generations.

This literature also hints at changes in population and household growth associated with gentrification. The initial steps of gentrification, particularly in contexts of urban renewal programmes, determine a reversal of the process of demographic and physical decline linked to the abandonment and stigmatisation of inner-city areas (Lees et al., 2008). For example, demographic decline was patent in run-down areas of the historic centre of Seville until the 1990s and was followed by a gentrification process that implied population growth and a decline in the number of vacant dwellings (Jover \& DíazParra, 2019). However, gentrification may also cause population decline resulting from a decrease in the number of people living in each household. First-generation young gentrifiers challenged traditional family formations, and this entailed that gentrifying areas witnessed the growth of young adults living in one-person households (Ford \& Champion, 2000; López-Gay, 2008; Ogden \& Hall, 2004). Bailey and Robertson (1997) illustrate how in both Glasgow and Edinburgh between 1971 and 1981 their populations decreased because of a reduction in household numbers, itself the result of housing demolitions and the growing numbers of vacant properties. These authors further illustrate that after the implementation of urban renewal programmes between 1981 and 1991, although household numbers in fact increased by $10 \%$, population totals continued to fall because of reductions in the average size of households. Therefore, population growth is not an indicator of whether gentrification took place in a certain place, and it should be analysed in relation to household growth and composition.

In spite of the growth of tourism experienced by cities in the last three decades, the mechanism through which tourism causes population restructuring at area level, and the nature and magnitude observed, is still a moot point. Tourism is rather considered a sideeffect of area regeneration programmes that result in enhanced attractiveness for visitors and 'mobile consumers' (Boyle \& Hughes, 1991; Evans, 2009; García-Hernández, la Calle-Vaquero, \& Yubero, 2017; Jansen-Verbeke, 1998; Pappalepore, Maitland, \& Smith, 2010; Russo \& Capel Tatjer, 2007). In fact, accounts of gentrification related to processes of urban renewal make explicit references to the attraction of tourists as part and parcel of the neoliberal restructuring of the urban economy that generally comes at the expense of longstanding residents (Eisinger, 2000; Hall, 2013; Judd \& Fainstein, 1999). For instance, in cities such as Berlin, Amsterdam, London and New York, the development of tourism and gentrification went hand-in-hand and the spatial connections of both processes were highlighted by several authors (Maitland \& Newman, 2008; Novy, 2018; Terhorst, Ven, \&
Deben, 2003). Yet tourism is not considered in this literature as an autonomous driver of gentrification: it is gentrified areas that become attractive for tourism, and some works examine how this may unsettle first-wave gentrifiers (Russo \& Van der Borg, 2010; Tironi, 2009). Notwithstanding, not only do tourists tend to consume gentrifying areas but also mobile populations settle and gather in these neighbourhoods, such as international students, digital nomads (professionals who undertake remote work through the Internet and are not tied to a particular location) and young migrants (King, 2018; Malet-Calvo, 2018; Novy, 2018). More recently, centrally located gentrifying areas have been impacted by the rise of short-term rentals, leading to an increased displacement of residents and the inflow of transient visitors (Cocola-Gant \& Gago, 2019; Wachsmuth \& Weisler, 2018). These trends pose several challenges to the way we measure and conceptualise the population restructuring of areas that appear to be a melting pot of young, transient and transnational populations. Gentrification research has traditionally relied on longitudinal census data, but because of the speedy nature of the Airbnb phenomenon and transient disposition of transnational mobile populations, it is unlikely that census information released every 10 years will capture rapid migration flows and residential mobility patterns taking place in tourist cities. Furthermore, when tourism scholars have examined population movements towards cities, the focus has been on identifying the mobility practices of the newcomers (Novy, 2018; Williams \& Hall, 2000), but not how the arrival of mobile users was restructuring the population of the places in which they settle.

Against this background, we suggest empirical, methodological and theoretical advances to make sense of how tourism is restructuring the populations of neighbourhoods that have become popular destinations. Empirically, from a socio-demographic perspective, two main questions arise when it comes to studying the impact of urban tourism. Firstly, our analysis will attempt to show that tourism activity in certain neighbourhoods causes population decline linked to a decrease of inhabited dwellings. Urban scholars have recently suggested that the prepandemic excessive growth of tourism and short-term rentals involves a sharp wave of displacement of residents to such an extent that some areas are losing their residential base and tacitly becoming tourist clusters (Celata \& Romano, 2020; Cocola-Gant, 2016; Jover \& Díaz-Parra, 2019; Sequera \& Nofre, 2018 and 2019). This outcome was also suggested by tourism scholars such as Law (2002) and Ap and Crompton (1993), who concluded that in mature tourist destinations, residents tend to move out of the community and therefore that population decrease may occur. Other recent works discuss how residents of areas subject to high levels of tourism pressure shift their consumption patterns to avoid contact with tourists (Quinn, 2007) and eventually move out of certain neighbourhoods (Cocola-Gant, 2016; Colomb \& Novy, 2016; Pinkster \& Boterman, 2017; Zanardi, 2019). However, these studies lack demographic evidence to support such claims or the degree in which this process may have been taking place. Although it seems clear that for several authors, there is a process of out-migration of residents, the profile of the population moving out is less apparent in terms of age, education or professional categories. In addition, we know that in 
gentrification processes, population decline can result from a reduction of the household size and so the number of inhabited dwellings should be taken into consideration in any analysis. In relation to this, the surge of short-term rentals may be playing an important role. Not only has the sharing of apartment buildings between residents and visitors been identified as an important factor of distress for the community, but as landlords rent to visitors rather than to long-term residents (Cocola-Gant \& Gago, 2019; Wachsmuth \& Weisler, 2018), the rise of Airbnb and other platforms may have a significant impact on the number of households, potentially implying a reduction of dwellings occupied by 'permanent' populations.

Secondly, it is important to explore migration flows in areas impacted by tourism to have a clear understanding of the profile of individuals moving in and out of these areas. As mentioned above, a process of out-migration of residents may be taking place, but we aim to demonstrate that tourist areas are, at the same time, attractive to young transnational gentrifiers as a transitory period in their residential trajectories. In this respect, research that looks into the agency of tourism and other dimensions of human mobility in place transformation has been given a strong boost by the ground-breaking works of Urry (2000) and Sheller and Urry (2004). In particular, several authors examine the mobility and dwelling practices of transnational populations, such as lifestyle migrants, digital nomads and international students, who tend to settle in centrally located tourist areas (e.g., Benson \& O'Reilly, 2009; Cocola-Gant \& Lopez-Gay, 2020; Huete \& Mantecón, 2011; King, 2018; Malet-Calvo, 2018; Novy, 2018; Russo \& Capel Tatjer, 2007; Williams \& Hall, 2000). The expansion of such forms of temporary migration is noted to have a significant impact on the population restructuring of some neighbourhoods, leading to what authors have called transnational gentrification (Hayes, 2018; Sigler \& Wachsmuth, 2016). This refers to a process of area change in which the gentrifiers are migrants from the industrialised West who relocate to cities usually in lessdeveloped regions. In terms of socio-demographic profiles, the works of both Hayes (2018) and Sigler and Wachsmuth (2016) refer to the migration of North American retirees to Latin American destinations who usually invest in second homes, and therefore, their work is linked to classical accounts of lifestyle migration (Benson \& O'Reilly, 2009; Huete \& Mantecón, 2011; Montezuma \& McGarrigle, 2019). However, the transnational migration of young people moving to cities because of lifestyle choices has been growing particularly in the European Union since the introduction of free movement of people in the 1990s (King, 2018). Central areas of tourist destinations such as Berlin (Novy, 2018), Lisbon (MaletCalvo, 2018) and Porto (Carvalho, Chamusca, Fernandes, \& Pinto, 2019) have witnessed the arrival of an array of young transnational mobile populations that are increasingly transient because they seem to stay in these destinations as a transitory period before settling down. These mobile populations consequently access housing via the private rental market, and so they put further pressure on an already competitive housing market impacted by short-term rentals.

In sum, the increasing penetration of tourism may be leading to a particular form of neighbourhood change, characterised by a decrease of long-term resident populations, a decline in the total number of households and the arrival of transnational and transient young gentrifiers deploying a wide range of dwelling practices, from the short stays of visitors in apartments rented on digital platforms to the longer sojourns of the hypermobile lifestyle migrants, students and young professionals. For an interpretation of this process that situates it against the extant tourism-led gentrification literature, we will refer to the conceptual body of the 'mobilities paradigm'. This 'set of questions, theories and methodologies' (Sheller \& Urry, 2006, p. 210) emerged in the early 2000 s to denote an epistemological shift from society as sedentary towards one in which it is conceived as inherently mobile (Urry, 2000). One first key insight of this literature for our research question is the need to move from a visitor versus resident dichotomy towards a tourism mobilities perspective, which considers the entanglements of a wide array of human and nonhuman mobilities, some more rooted in place than others (Hannam, Sheller, \& Urry, 2006). In this sense, the category of 'gentrifier' in tourist cities includes a variety of mobile population profiles whose dwelling and life practices tend to match and converge spatially with those of the tourist population. Following authors such as Cresswell (2006), Cresswell and Merriman (2011) and Jensen (2010), a second fundamental insight for our inquiry is that the transformation of tourist areas could be interpreted as the result of a negotiation played out in the economic as well as in the material and cultural dimensions of places, whereby more wealthy, footloose, physically able and digitally competent populations gain access and control of urban assets (such as housing and commercial facilities) and commons (such as public space and public life) over less mobile and more dependent populations. We therefore suggest that the population restructuring of tourist areas may well be the result of a process of neighbourhood change that caters to the practices and affordability of the flow of young gentrifiers on the move, leading to the out-migration of more permanent populations not only because the area may become unaffordable for them but also because the change becomes incompatible with their dwelling practices. Hence, our approach to the analysis of tourism-led gentrification highlights the mobile character of gentrifiers-and by contrast, the 'immobility' of resident populations which are displaced in the process-and interprets our empirical results, characterising tourism-led gentrification as a shift from 'classical' gentrification, in the broader framework of a relational epistemology. We now explore these transformations in the city of Barcelona, starting in the next section with a presentation of our case study area and further advancing our conceptual contribution in the discussion section.

\section{3 | METHODOLOGY}

\subsection{Presentation of case study: Barcelona and Barri Gòtic}

According to the MasterCard Global Destination Cities Index (2017) Barcelona ranked 12th in the world and third in Europe (behind 
London and Paris) in terms of international overnight visitors. In 2017, 7.7 million overnight visitors checked into hotels, totalling almost 20 million overnight stays-four times higher than the figures recorded in 1993 and twice as many than in 2005 (www.bcn.cat/ estadistica). The total number of overnight stays exceeded 32 million when holiday rentals are included (Barcelona City Council et al., 2017).

For local authorities, establishing Barcelona as a tourist destination has been a strategic aim in the restructuring of the city since the late 1980s (Balibrea, 2001; Russo \& Scarnato, 2018; Smith, 2005). As a result, there has been a significant growth in tourism, which occurred particularly after the year 2000 and further intensified after 2010. The neoliberal answer to the post-2008 crisis was the promotion of more tourism and, importantly, the licensing without restrictions of tourist-oriented activities, such as terraces in public spaces, restaurants, bike and Segway-rental shops, cruise ships and hotels. Furthermore, Airbnb was established in 2008; therefore, this period witnessed the spread of short-term rentals and the increased use of housing as tourist accommodation. In 2011, the number of Airbnb listings in Barcelona was circa 3,000, growing to 16,000 in 2015 and reaching a peak of more than 18,000 in 2018 (Sales, 2019). The excessive growth of tourism resulted in the rise of community protests, not just in the city centre but in several neighbourhoods across the city. The current COVID-19 pandemic has produced a global collapse of tourist flows in urban areas. In spite of the current debate on the future of tourism and whether this crisis has brought about a new consciousness of the urgency of a transition towards more tourism-resilient places (e.g., Haywood, 2020), it is also noted that-especially in the most tourism-dependent countriesthe pressure to go back to business-as-usual once the sanitary emergence is over is very strong (Bianchi, 2020; Hall, Scott, \& Gössling, 2020).
We have chosen the Barri Gòtic (Gothic Quarter, henceforth denoted just as Gòtic), located in the historical centre of Barcelona, as our case study. The Gòtic is one of the 73 neighbourhoods in which the municipality of Barcelona (which has 1.6 million residents in a $100 \mathrm{~km}^{2}$ area) is administratively divided. The neighbourhood is the oldest part of Barcelona and hosts some of the most iconic attractions and must-see sites of the city. This has resulted in the growth of tourism-oriented services across the neighbourhood, particularly restaurants, hotels and holiday rentals. Figure 1 shows that the Gòtic is the most touristified area of Barcelona. Considering that 64 hotels, 50 hostels and 1,194 Airbnb listings existed in the neighbourhood in 2018, the result is that there are 71 beds offered to tourists per 100 inhabitants, meaning that the intensity of tourism in the area is substantially higher when compared with the rest of the city. Moreover, its proximity to the port means that it is visited by a large share of its yearly 2.7 million cruise passengers as well as frequented on the way to other attractions (Brandajs \& Russo, 2019).

The gentrification of the Gòtic started in the early 1990s. Subsequent censuses show that the mostly Spanish pioneer gentrifiers have been progressively replaced by transnational migrant gentrifiers (Arbaci \& Tapada-Berteli, 2012; Cocola-Gant \& Lopez-Gay, 2020). Notwithstanding, gentrification is still ongoing, and elderly residents with lifetime tenancy agreements living in run-down apartments do exist in the neighbourhood. At the same time, residents in this area have been complaining about tourism since the early 2000s (CocolaGant, 2016). Protests have been more widespread since 2010 as the result of the deregulation of tourism-oriented services, following on from anti-crisis reforms. These policies have led not only to further growth and concentration of tourist activity but also to the increasing reorientation of housing and commercial supply for the demands of visitors. Citizens and grassroots entities are particularly concerned with the induced changes in the social fabric of the neighbourhood.
FIGURE 1 Number of tourist beds per 100 inhabitants in the 73 neighbourhoods of Barcelona, 2018 (the neighbourhoods included in the study are highlighted). Source: own elaboration from data collected by Sales (2019). Includes all beds offered in hotels, hostels, pensions and tourist apartments

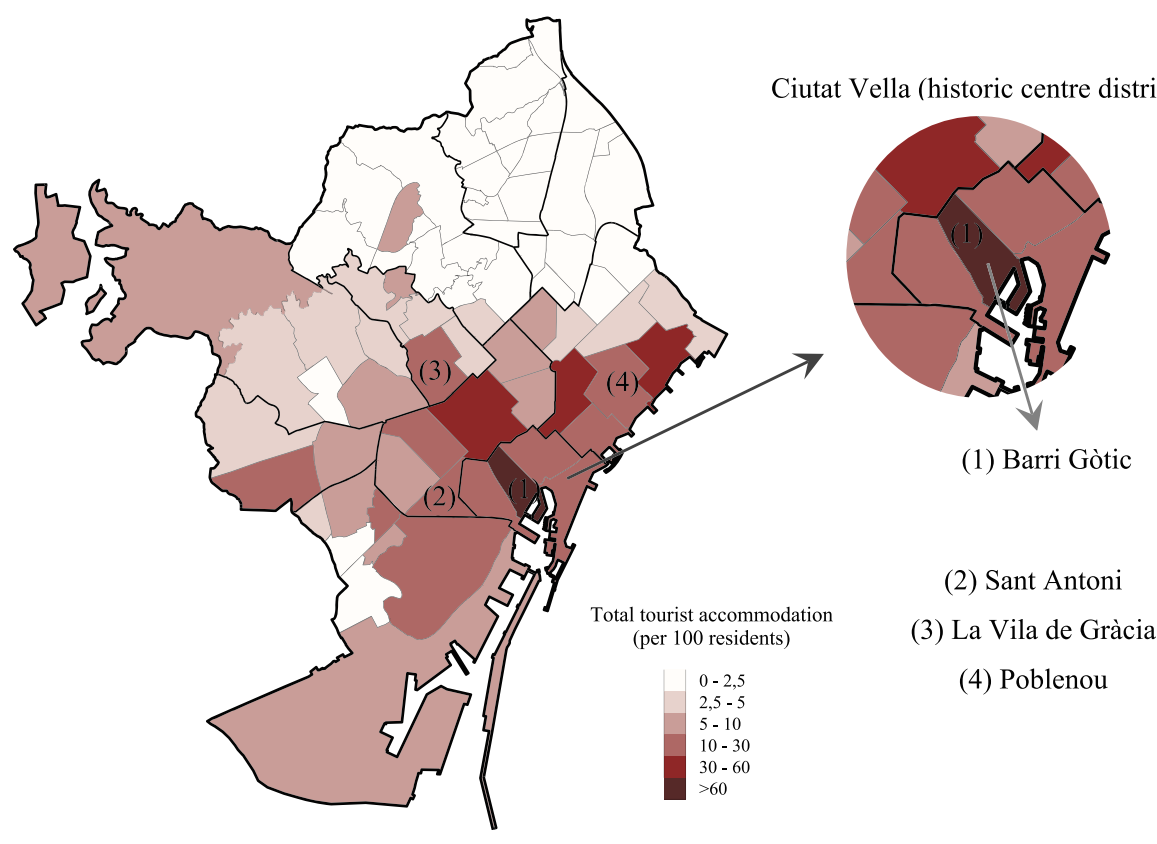


Their mottos often refer explicitly to the demographic implications of tourism, for example, 'neighbours, a species threatened with extinction'; or 'more tourist apartments, fewer families'.

\section{2 | Research design and analytic methods}

Our research uses a mixed-method approach that combines demographic analysis with in-depth interviews. A significant part of the investigation focuses on quantitative data, exploring (i) household and population variations at an area level and (ii) the characteristics of out-migrant and in-migrant cohorts. We then compare the results of the quantitative analysis of our case study with other neighbourhoods in the city that are undergoing gentrification processes but experience less tourism activity (Figure 1). The aim of this comparison is to explore whether any differences occur between population change in processes of tourism and classical gentrification. Finally, in-depth interviews are used to better interpret the results from the quantitative analysis, thus unravelling the relationship that the increasing penetration of tourists in these areas may have with such dynamics.

In terms of the sources used, because of the limitations of the census, the data are from the Spanish Population Register (INE and Statistics Department of Barcelona City Council). We used annual counts for the population living in the municipality by age, sex, citizenship and place of birth, as well as household data from the beginning of the Population Register in 1998 up until 2017. The dataset of Barcelona City Council (BCC) defines a household as every dwelling occupied by, at least, one registered resident. BCC also provided us with a 6-year register-based database (2011-2016), which includes information about sex, age, citizenship, place of birth and educational attainment of each individual that has moved into, within, or out of the area under examination. We have also used the 2017 Barcelona Socio-Demographic Survey that allows us to capture additional characteristics of residents, independently from their affiliation to the population register. The sample size is 10,415 individuals. Relying on both the population register and the 2017 Barcelona Socio-Demographic Survey, we have created a set of indicators to measure the transient character of residents and migration flows in the area. These indicators will be described in the analysis. Additionally, to map the supply of tourism accommodation, we relied on data scraping from the Airbnb website undertaken by Sales (2019). We further conducted 42 in-depth interviews with residents living in the area for at least 5 years, 16 of which were transnational migrants from Western Europe and the United States. We asked residents about how tourism has been impacting the neighbourhood since the 1990s and the way in which they have adapted over time to such changes. Interviews with migrants also focused on personal reasons for settling in the area and about their motivations behind moving to Barcelona. We initially recruited participants by personal contacts in the neighbourhood, and from this starting point, respondents were asked to recruit another contact, thus triggering a snowballing effect. The snowball effect provided us with the possibility to contact residents living in the area for more than 25 years. Interviews were mainly conducted in Spanish. Some interviews with transnational migrants were conducted in English.

\section{4 | RESULTS OF THE ANALYSIS}

\section{1 | Population and household growth: a shrinking neighbourhood}

In this first subsection, we explore changes in the number of inhabitants and households in order to analyse whether there is a link between high levels of tourism activity and a decrease in the number of residents. The Spanish Population Register series started in 1998. At this point, the Barri Gòtic had 15,000 inhabitants. Soon after, the number of residents increased rapidly because of the growth of the foreign population. However, part of this increase was linked to an anomaly in the registration process. The City Council registered in the headquarters of the Statistical Department, which is located within the Barri Gòtic, all foreign citizens arriving in Barcelona who did not have a permanent address. As a consequence, the census tract where this department is located experienced an unprecedented growth in the number of inhabitants (Bayona, 2006). The rapid population growth between 2000 and 2007 is the result of this anomaly. In 2008 , the Statistics Department started to debug the data, and in 2012, the effect of the previous irregular procedure was eliminated. We have proceeded to correct the population series with a linear interpolation from 2001 to 2012 of the population with foreign nationality in the census tract in which the overregistration was observed. In this new series (Figure 2), the population peaked between 2008 and 2010 at around 18,000 inhabitants. However, following this, the population decreased to 15,400 individuals registered in 2015 . Although recently the population grew by 600 inhabitants between 2015 and 2017, this increase is associated with another anomaly as vulnerable foreign populations have been registered in the census tract where the Social Services of the district is located. Thus, the total number of residents has decreased $7.5 \%$ during the period $2011-2017$ (12.2\% if the Social

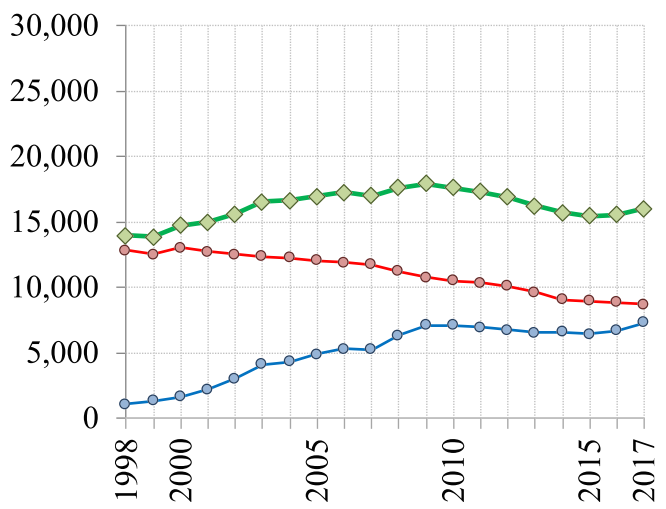

$\curvearrowright$ Total population $\quad \circ$-Spanish nationals $\quad \circ-$ Foreign nationals

FIGURE 2 Evolution of the population in the Barri Gòtic by citizenship. Source: Population Register, 1998-2017 
Service's census tract is not included), whereas the population in the entire municipality of Barcelona has remained stable, recording a slight increase of $0.3 \%$. Importantly, Spanish individuals and foreign nationals have experienced differing trends since 1998: The former population has decreased by 4,200 individuals, and the latter has increased by 6,000 .

It is well known that population decline does not necessarily equate to a decrease in the number of households nor negative net migration. An aged population can also contribute to a decrease in the number of residents because of high death rates. This certainly was the case of the Gotic at the end of the twentieth century (Ajuntament de Barcelona, 1999). For this reason, we examine the recent evolution in the number of households living in the neighbourhood (Table 1). As the household series are also constructed from the Population Register, anomalies are also noted, namely, a large number of households with nine or more members in 2007 and a significant decrease between 2007 and 2011 because of the aforementioned debug of the register. In 2011, the number of households in the neighbourhood was around 7,000, compared with the 6,500 recorded in 2017, equating to a $6.8 \%$ decline over 6 years, when, in Barcelona as a whole, the number of households during the same period has remained stable. The high number of one-person households could be seen as a sign of the gentrification of the area (more than $70 \%$ of these households are composed of adults aged 18-65), but they too have decreased since 2011. This figure reveals that the decline in population witnessed after 2011 is mainly related to a fall in the number of occupied dwellings and not to an increase in single-person households as is generally the case in classical gentrification (Ogden \& Schnoebelen, 2005). Interestingly, recent quantitative research across the 73 neighbourhoods in Barcelona found a spatial correlation between the growth of short-term rentals and the decrease in households, emphasising that the process is particularly intense in the Gotic (Sales, 2019). This supports our assumption that part of the residential housing stock of the area has been replaced by other uses. The results of the qualitative research will further confirm this outcome.

Therefore, the area has been experiencing a process of population and household decline since 2011, whereas no other neighbourhood in Barcelona (out of 73) experienced a higher decrease in the number of residents and households during this period. Those neighbourhoods ranking just below are other central and tourist areas, such as la Barceloneta or el Raval, which experienced a decrease of around 3\% in their number of households. This is far from the figures of the Gòtic but is consistent with our hypothesis. Despite this decrease, it is important to mention that the process does not mean that the residential base of the area has been replaced by visitors, even if this is the most touristified area of the city. It seems that Spanish residents have been moving out although the area has become attractive to foreign nationals. In the section below, we further explore this issue.

\section{2 | Socio-demographic changes: transnational and transient gentrifiers}

In this subsection, we examine socio-demographic shifts in the population of the Barri Gòtic using four variables: sex, age, nationality and level of education. Our analysis here aims at highlighting residential selection and migration flows in a tourist area, which ends in changes in the composition of the population living in the neighbourhood. We start by comparing the population pyramids of 1998 and 2017 (Figure 3). The transformation that the population structure has experienced over the past 19 years is extraordinary. The number of over $65 \mathrm{~s}$ has halved, and the 25 to 39 age group has become the largest section of the population pyramid. In 1998, the latter age group represented $23 \%$ of the population but now constitutes $37 \%$ and includes significantly more men than women. Despite this increase in the adult population, the base of the population pyramid has not experienced any change, and only $8.4 \%$ of the population is under the age of $15-$ the lowest percentage among the 73 neighbourhoods of the city. It is also by far the area with the highest ratio of adults (25-59) to children (0-14): 7.6 compared with the city's average of 4.1 .

The increase in the number of people aged 25 to 39 is due almost exclusively to the arrival of foreign nationals, which account for $69 \%$ of this age group. The presence of Western European citizens is particularly high, especially individuals from France, the United Kingdom and Italy. Europeans currently represent more than half of the foreign nationals in this age group. The percentage of native people (those born in the province of Barcelona) in the 25-39 age

TAB LE 1 Evolution of the number of households in the Barri Gòtic by size, 2004-2015

\begin{tabular}{|rrrrrrrrrrrrrrrrrr}
\hline & 2004 & 2005 & 2006 & 2007 & 2008 & 2009 & 2010 & 2011 & 2012 & 2013 & 2014 & 2015 & 2016 & 2017 \\
\hline 1 & & 2,780 & 2,779 & 2,727 & 2,674 & 2,641 & 2,683 & 2,724 & 2,668 & 2,628 & 2,567 & 2,526 & 2,533 & 2,587 \\
2 & 1,889 & 1,907 & 1,827 & 1,844 & 1,862 & 1,923 & 1,930 & 1,942 & 1,925 & 1,867 & 1,865 & 1,818 & 1,826 \\
\hline 3 & 1,024 & 1,009 & 990 & 998 & 986 & 1,098 & 1,068 & 1,018 & 1,019 & 989 & 918 & 945 & 949 \\
\hline 4 & & 662 & 667 & 635 & 635 & 655 & 666 & 620 & 605 & 620 & 603 & 587 & 586 & 607 \\
\hline $5-8$ & & 487 & 519 & 453 & 483 & 564 & 589 & 529 & 543 & 551 & 511 & 467 & 488 & 491 \\
\hline $9+$ & & 462 & 447 & 481 & 422 & 393 & 169 & 141 & 116 & 87 & 101 & 98 & 80 & 77 \\
\hline Total & 7,196 & 7,304 & 7,328 & 7,113 & 7,056 & 7,101 & 7,128 & 7,012 & 6,892 & 6,830 & 6,638 & 6,461 & 6,450 & 6,537 \\
\hline
\end{tabular}

Source: Annual release of the Population Register, at date 30-VI. Statistics Department of Barcelona City Council. 
1998

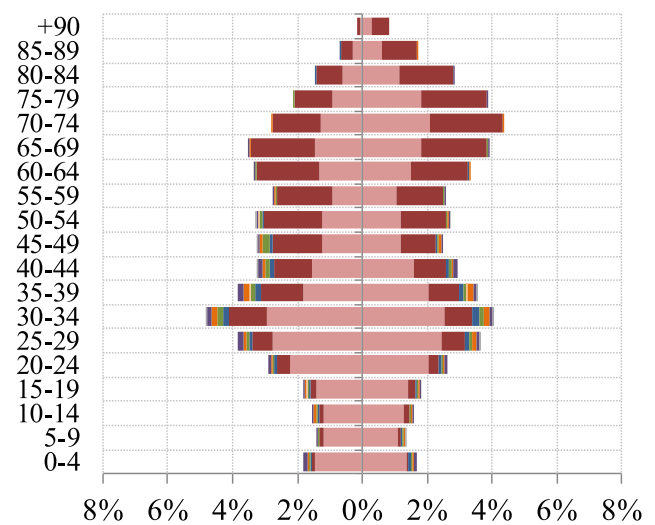

2017

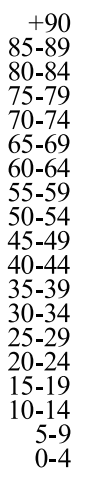

$\begin{array}{llllllllll}8 \% & 6 \% & 4 \% & 2 \% & 0 \% & 2 \% & 4 \% & 6 \% & 8 \%\end{array}$
FIGURE 3 Population structure of the Barri Gòtic by nationality, 1998-2017. Source: Population Register
- Spain (born within prov.)

$$
\text { Africa }
$$$$
\text { - Asia }
$$

- Spain (born outside prov.) North America - Others

\section{- Europe \\ - Latin America \& Carib.}

group is extremely low, constituting just $14 \%$ of the population, and is an unusual feature of the city (the city-wide average for this age group is $45.1 \%)$. This clearly reflects the infrequency in which young locals include this neighbourhood in their residential strategies. Furthermore, previous studies have also shown that this area is not a popular destination for highly educated individuals moving to Barcelona from elsewhere in Spain as it is for high-skilled transnational migrants (López-Gay, 2016).

These data show that the progression of gentrification in the Gòtic is not homegrown but transnational. The elderly have been replaced by young adults with low fertility. However, the arrival of young adults in the area is linked to transnational migration flows, whereas Spanish residents have been moving out. For this reason, the analysis of migration flows and residential mobility are central for a better understanding of socio-demographic changes in the neighbourhood. We explore the most recent flows of population by level of education and nationality below (Figure 4).

The first point to consider is that between 2011 and 2016, the Gòtic lost Spanish citizens of all ages except the highest educated young adults. However, this positive net migration is very low. The rest of the age groups experience negative net migration, regardless of educational attainment. Secondly, the net migration of European citizens is also positive among young adult age groups, and it is remarkably higher than any other origin. In addition, the positive net migration of young individuals with secondary-level education is remarkable, hinting possibly at the attractiveness of the neighbourhood for Erasmus students and other international undergraduate groups. Finally, negative net migration of extra-EU individuals is evident, especially among the least educated. Therefore, the Gòtic experiences a process of gentrification in which the newcomers are predominantly highly educated young migrants, and the population leaving is the less educated, particularly Spanish residents.

Migration flows also show significant changes in the elderly and under 18 populations, especially among Spanish citizens. The population loss experienced among those groups is significant.
Firstly, the negative net migration registered at the top of the pyramid indicates that the population rejuvenation is not just the effect of mortality but also the consequence of the out-migration of the elderly from the area. Secondly, the fact that in the population pyramid the number of children is rather low is not just related to the presence of small households and low fertility, which may be the case observed in many other examples of gentrified neighbourhoods (Ford \& Champion, 2000; Ogden \& Hall, 2004; Ogden \& Schnoebelen, 2005). Instead, data show a significantly negative net migration of children, which suggests that families may be leaving the area. In fact, the 35-49 age group experiences the highest negative net migration, even among European residents. As in other cases of gentrification, this suggests that young gentrifiers that arrived in the previous decade may be moving out once they have children.

We further show how highly mobile young individuals play a major role in the population restructuring of the neighbourhood. Transient populations are harder to trace than more nontransient residents. To overcome this limitation, we have created a set of indicators (Table 2). The first four use data from the residential and migratory flows belonging to the population register. The annual inflow rate including any type of arrival into the area doubles the average rate of the city, meaning that the area is significantly attractive for new residents. In addition, arrivals from other municipalities and countries play a major role compared with the rest of the city. The out-flow rate to other neighbourhoods within Barcelona also doubles the average rate of the city. Comparing the two rates, the Gòtic's overall net migration is slightly negative, but the figure reaches very strong negative values when we only consider movements within the city. This reveals that the area seems to be the arrival point for individuals from outside Barcelona but who are likely to move out soon afterwards to settle in a different area of the city. In other words, the Gòtic is an area with high levels of population mobilityhigh rates of people moving in but who are unlikely to settle for a long period-which results in an increased number of transient residents. 
FIGURE 4 Average annual flows (outflow and inflow) and net migration by age, educational attainment and nationality in the Barri Gòtic, 2011-2016. Source: Registered inflows and outflows by the Statistics Department of Barcelona City Council
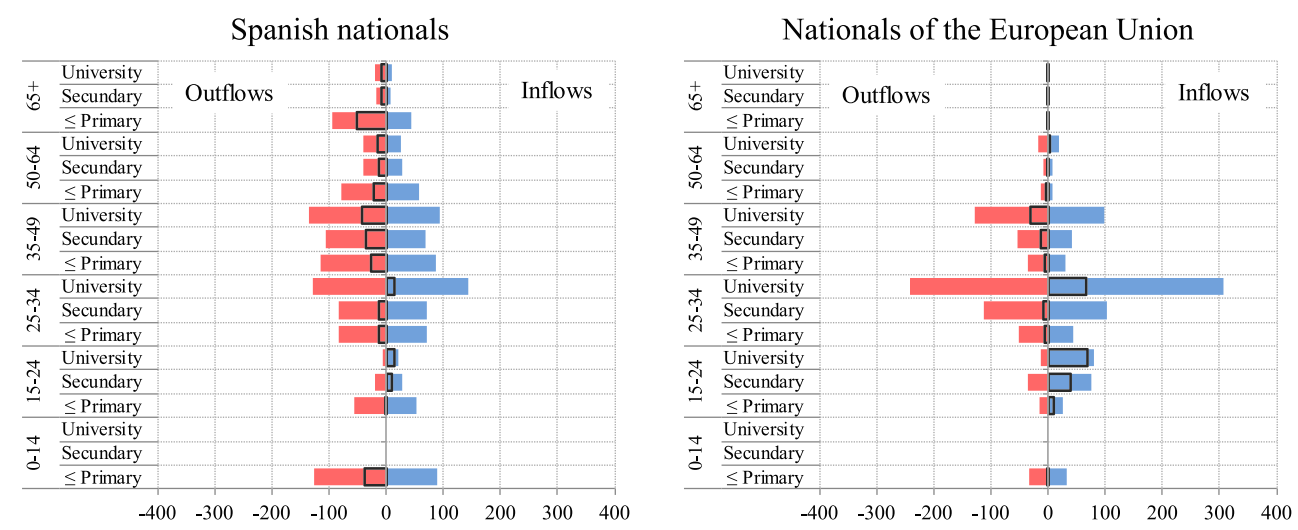

Not European Union nationals

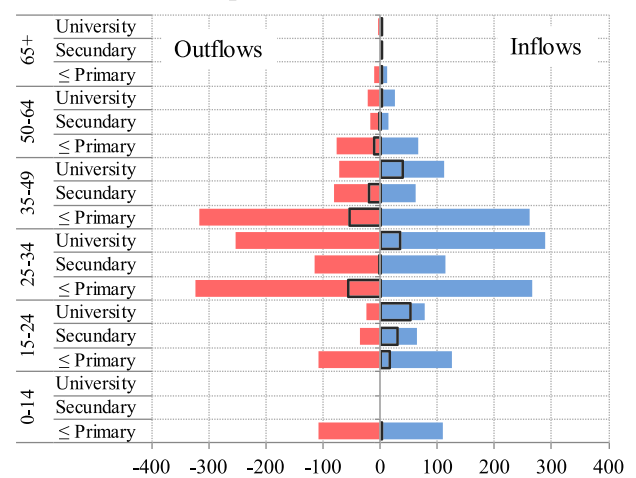

All the population

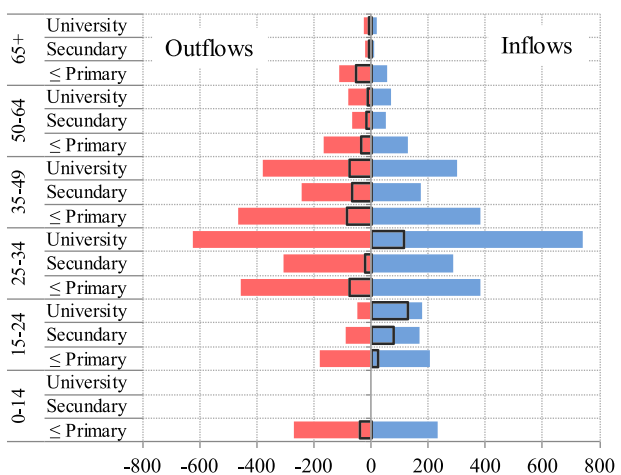

$\square$ Net Migration $\quad$ Outlfow $\quad$ Inflow

TABLE 2 Set of indicators regarding migration, residential mobility and transient populations

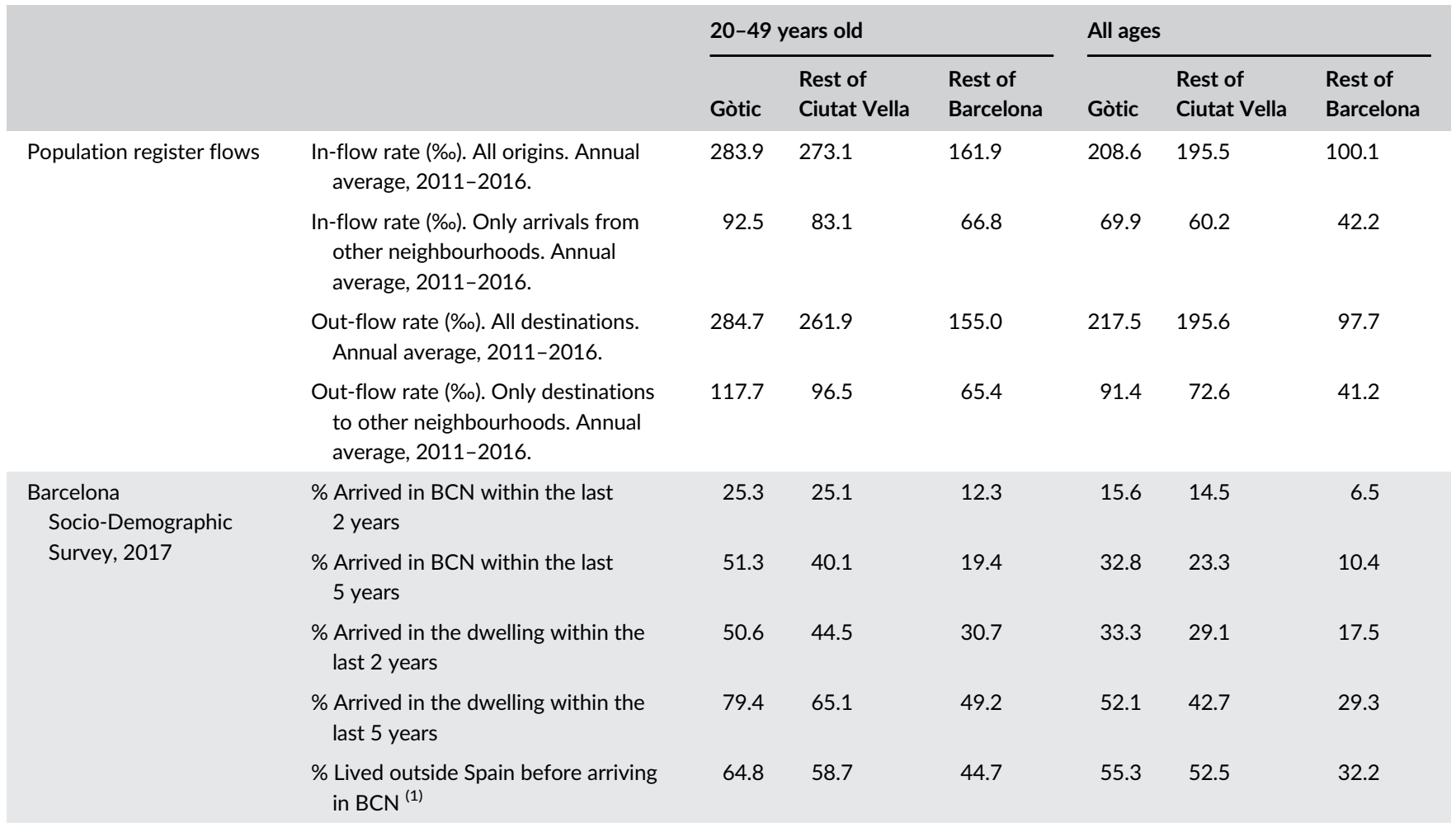


TABLE 2 (Continued)

\begin{tabular}{|c|c|c|c|c|c|c|}
\hline & \multicolumn{3}{|c|}{$20-49$ years old } & \multicolumn{3}{|c|}{ All ages } \\
\hline & Gòtic & $\begin{array}{l}\text { Rest of } \\
\text { Ciutat Vella }\end{array}$ & $\begin{array}{l}\text { Rest of } \\
\text { Barcelona }\end{array}$ & Gòtic & $\begin{array}{l}\text { Rest of } \\
\text { Ciutat Vella }\end{array}$ & $\begin{array}{l}\text { Rest of } \\
\text { Barcelona }\end{array}$ \\
\hline $\begin{array}{l}\text { \% Not registered in the Spanish } \\
\text { Population Register }\end{array}$ & 11.5 & 4.0 & 1.0 & 6.5 & 2.3 & 0.6 \\
\hline $\begin{array}{l}\% \text { Foreign born with university degree } \\
\text { (2). Age group } 25-49\end{array}$ & 49.1 & 41.0 & 34.5 & & & \\
\hline
\end{tabular}

Source: Registered in-flows and out-flows (2011-2016) and Barcelona Socio-Demographic Survey, 2017 (Statistics Department of Barcelona City Council). Note: All indicators from the Barcelona Socio-Demographic Survey are calculated out of all the individuals, except (1) among the individuals that ever lived outside Barcelona and (2) among all the individuals that arrived in the dwelling within the last 5 years.

In order to provide more evidence on this dimension, we created a second set of indicators relying on the 2017 Barcelona SocioDemographic Survey. This survey offers information about the year of arrival in the neighbourhood and in the dwelling, among other characteristics. Half of the surveyed population in the Gotic arrived in their dwelling of residence within the last 5 years, reaching an astonishing $79.4 \%$ for the $20-49$ age group, whereas the average in Barcelona is $29.3 \%$ and $49.2 \%$, respectively. Results of the other indicators regarding these variables confirm the substantial differences between the Gòtic and the rest of the city. Furthermore, we calculated the percentage of people who lived outside Spain before moving into the city. Results show that $55.3 \%$ of residents in the Gòtic fit in this category, whereas the average in the city is $32.2 \%$. Importantly, for the 20-49 age group, this figure reaches $64.8 \%$ in the Gotic but in the rest of the municipality is $44.7 \%$. Therefore, it seems that the percentage of transient residents is particularly high among young transnational populations. Finally, the proportion of individuals declaring that they are not registered in the Population Register (compulsory for every inhabitant of Barcelona, no matter the legal status is) is a good indicator of the specific attractiveness of the Gòtic for transient dwellers: $6.5 \%$ of the neighbours are not recorded by the Spanish Population Register, a proportion that is superior to a factor of 10.0 to those living in other city neighbourhoods. In Barcelona, almost half of this group is foreign born, has a university degree and has arrived in Barcelona within the last 2 years.

In sum, the area has experienced a process of population restructuring whereby increasingly transient young transnational gentrifiers replace Spanish residents, particularly the elderly, families with children and those with lower levels of educational attainment. Among transnational gentrifiers, data show that they are unlikely to be retirees but rather young graduates and international students that fuel the fast mobility and transient character of visitors. Importantly, the decrease in the total number of residents and households should not be linked to the attractiveness of the neighbourhood. The flows moving into and out of the neighbourhood are more intense than in the Barcelona average, and this is inherent to the floating and transient nature of the dwellers of the Gòtic. The decrease in population and households is therefore the result of out-migration from the neighbourhood. In the next section, we compare these results with other gentrified areas of Barcelona and better illustrate the extent to which such population changes seen in the Gòtic are unique.

\section{3 | Contrasting gentrification trends in Barcelona's neighbourhoods}

In this subsection, we compare the socio-demographic changes observed in the Barri Gòtic with population dynamics in Sant Antoni, Vila de Gràcia and Poblenou (Figure 1). These three neighbourhoods are experiencing intense gentrification processes (Porcel, 2016) but are not exposed to the same pressure from tourism as in the Gotic. None of these, in fact, have experienced population decline as intensely as the Gotic. Vila de Gràcia is the only neighbourhood that registered a population decrease (and a drop in the number of households) between 2011 and 2017 but at a much slower pace than in the Gòtic $(-1.1 \%$ compared with $-7.5 \%)$. The population pyramids in 2017 (Figure 5) and migration flows registered during the period 2011-2016 (Figure 6) show that these three neighbourhoods have (i) a high proportion of young adults, (ii) a significant presence of European citizens and (iii) high levels of residents with university degrees. These three indexes coalesce in a positive and aboveaverage net migration rate of the highly educated.

However, in the Barri Gòtic, we identified some features that are not found in these three neighbourhoods. Firstly, the number of young local adults, born within the province of Barcelona, is much higher than in the Gòtic, where they represented $14 \%$ of the resident population. In Poblenou, they account for $45 \%$ of the population aged 25-39; in Vila de Gràcia, this figure is 39\%; and in Sant Antoni, it is $35 \%$. Consequently, there tend to be fewer European residents in these three neighbourhoods compared with the Barri Gòtic: Although Europeans are the largest group among the foreign citizens, they do not account for more than $20 \%$ of the total population of this age group (which is half of the percentage observed in the Gòtic). Thus, the first thing to note is that gentrification in these neighbourhoods is more homegrown and less transnational.

Secondly, the presence of children in the three neighbourhoods is also low compared with the Barcelona average but still much 

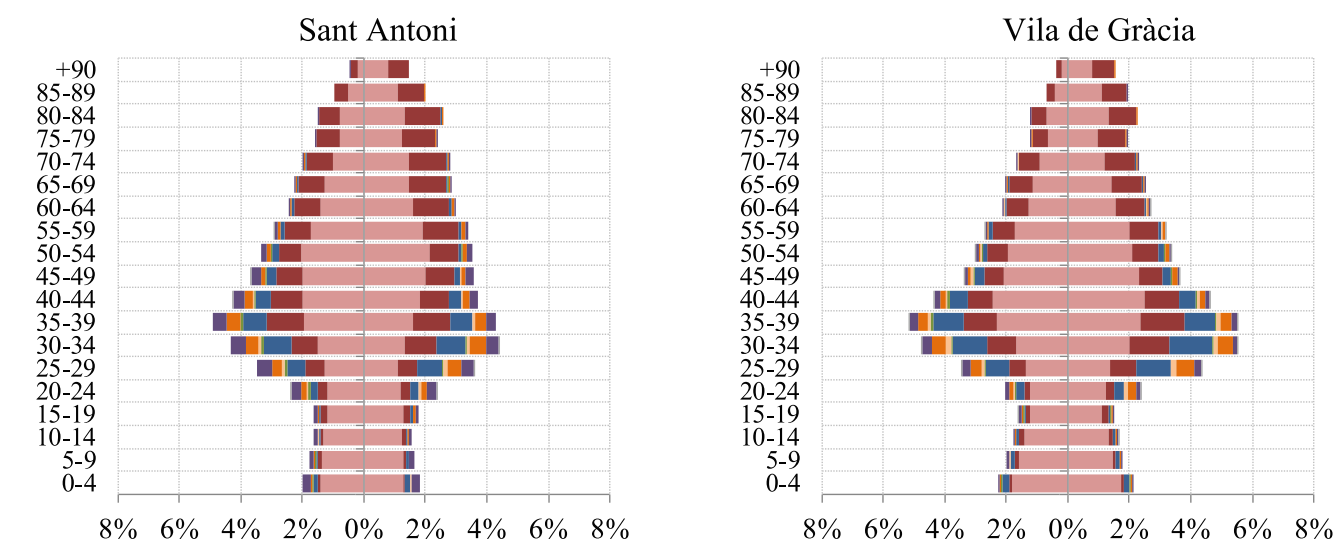

Poblenou

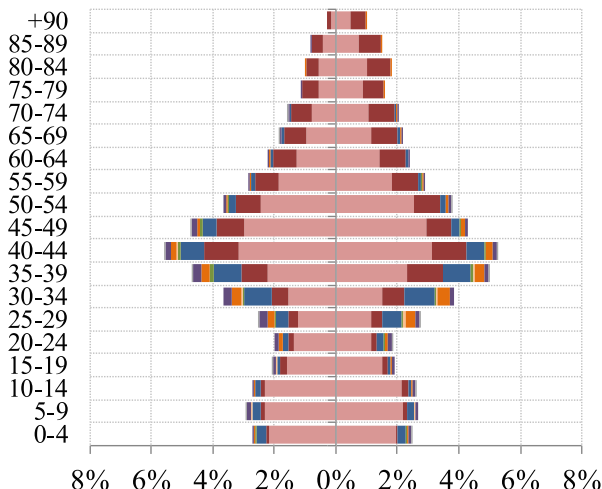

Spain (born within prov.)
Africa
Asia

- Spain (born outside prov.) North America

Others

FIGURE 5 Population structures by nationality, 2017. Source: Population Register

higher than in the Gòtic. The ratio of adults (aged 25-59) per child (aged 0-14) in Sant Antoni-the highest in these neighbourhoods-is 5.1, and in Poblenou, it is 3.2, whereas in the Gotic, it is 7.6. In contrast with the negative net migration of minors observed in the Gòtic area, Poblenou experienced positive net migration (Figure 6). In Sant Antoni and Vila de Gràcia, the in-migration rate of the younger age cohort is slightly negative but far less so than in the Gòtic, where the annual net migration rate of the $0-14$ age group is $-27.3 \%$ (the neighbourhood loses 27 children out of 1,000 every year because of residential mobility and migration), and in Vila de Gràcia, the figure is $-12.6 \%$. Therefore, although gentrifiers may move out as they have children (Hochstenbach \& Boterman, 2018), the extent to which this process takes place in the Gòtic is significant, highlighting how gentrification is driven by young and transient newcomers.

Regarding the patterns seen in the residential and migratory flows, none of these neighbourhoods experienced population loss similar to the Barri Gòtic, which affected all age groups except the youngest adults with a range of educational attainments. Finally, in terms of the 65+ age group, the average annual net migration during the period 2011-2016 in the Gòtic was $-31.1 \%$, whereas in Sant
Antoni-the area with the lowest net migration among the ones we selected-it was $-12.6 \%$. Consequently, although negative net migration of the elderly is a feature of gentrification, the intensity in which this process occurs in the Gotic area is particularly high.

In sum, the changes taking place in the Barri Gòtic present a number of socio-demographic features that are alien to the most common patterns of population change observed in gentrified neighbourhoods, even in the city of Barcelona. We suggest that these particular changes in the population witnessed in the Gotic neighbourhood are linked to the pressure from tourism that the area experiences. We turn now to examine the results of the qualitative exploration in order to further develop this point.

\section{4 | Living in a tourist neighbourhood}

In this last subsection, we present the results from interviews to examine to what extent the decrease of population and households could be linked to the excessive growth of tourism activity and to provide further insight on the process by which floating transnational 
Sant Antoni

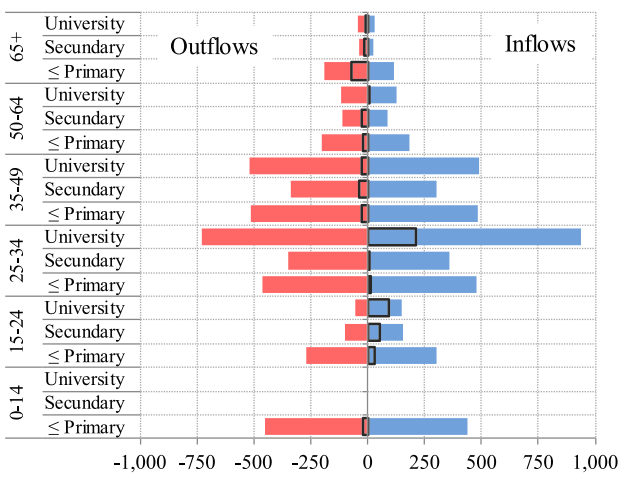

Vila de Gràcia

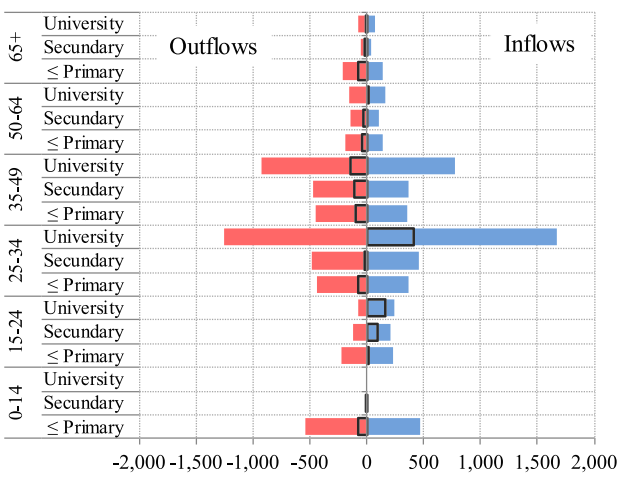

FIGURE 6 Average annual flows and net migration by age and educational attainment, 2011-2016. Source: Registered inflows and outflows by the Statistics Department of Barcelona City Council

Poblenou

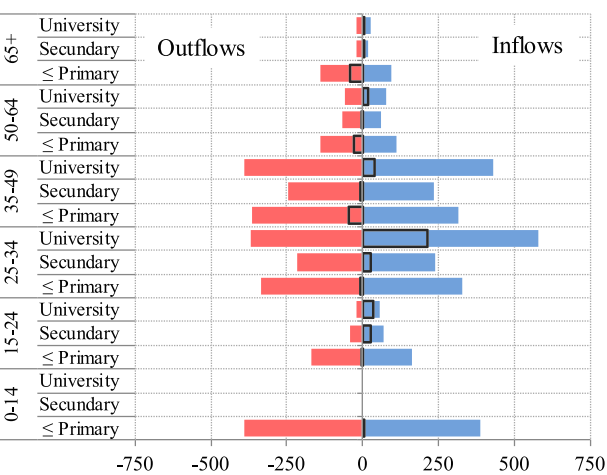

$\square$ Net Migration $\quad$ Outlfow Inflow

populations become enmeshed in processes of gentrification in tourist areas.

Regarding the first issue, all participants, including transnational migrants, depict a process of population flight. Tourism makes the area increasingly unliveable, and a common strategy adopted by residents is to simply move out. Our participants were living in the area for at least 5 years, and they explained how their social networks have been shrinking as a result of the above. Therefore, it is important to note that population flight particularly affects long-term residents. As a participant stated, 'most of the people we know have gone because they were tired of living here'. This confirms the suggestions from the literature that, in neighbourhoods impacted by tourism, one approach that residents follow is withdrawal (Ap \& Crompton, 1993; Colomb \& Novy, 2016; Pinkster \& Boterman, 2017). Interviews reveal that gentrifiers who arrived in previous years are also moving out, especially once they have children. In understanding this process, we find two interwoven key factors. Firstly, daily disruptions caused by tourism make the area less and less attractive for certain residential routines, which generally characterise the long-term resident population. The main disruptions that we identified were noise, overcrowding of public spaces and lack of commercial services. Noise is the most dramatic factor highlighted by all participants, and this has also been noted in other tourist areas of the city (Nofre, Giordano, Eldridge, Martins, \& Sequera, 2018). Several residents stated that they are unable to sleep, and noise was presented as a public health issue that affects the daily well-being of the community:

We deal with noise very badly. Shouting all night in the streets, parties in holiday apartments, cleaning services, music coming from pubs, etc. It is unliveable here.

Exclusion from public spaces is a point of distress as well. On the one hand, the proliferation of tourist-oriented terraces corresponds to an increasing shortage of spaces to rest and sit on. On the other hand, overcrowding and mobility issues, caused by the large number of visitors-many of which use bikes or Segways to move around-are seen by participants as undermining the well-being of the population, particularly the elderly and children. Interviews with elderly residents reveal that they tend to be isolated at home because: (i) There are no places for them to rest in the street; (ii) walking on their own may be dangerous because of overcrowding; (iii) they do not have places to go to. For children, overcrowding means that it is dangerous to play in public spaces even if the entire neighbourhood is a vehicle traffic-free area. The overcrowding of public spaces is related to changes in retail services too. Commercial facilities in the neighbourhood increasingly cater to mobile populations, whereas services used by 'sedentary' residents tend to disappear. This is clearly evident in regard to retail facilities, which place-dependent residents need on a daily basis, 
including bakeries, greengrocers and even pharmacies. The change in retail implies that residents need to walk to other neighbourhoods to access daily products, which is a significant disruption for the elderly and for people with children as the overcrowding of public spaces makes it increasingly difficult for them to move around. As women often have caring responsibilities, we noted that female residents were particularly affected by these issues. As a female resident stated:

Yes, I know people who have left. It is a permanent flight [of people]. And they have left because of noise, lack of facilities, mobility problems, especially if you have children. This is not a place to have children. Taking your children to school without distress is important! It becomes a daily fight.

The second issue in understanding the decrease in population and households is the conversion of housing into short-term rentals, meaning that apartments have been taken away from the market for long-term residents. In the Gòtic area, grassroot movements claim that holiday rentals were the cause of evictions as early as 2005 , but interviewees state that the process grew significantly after the expansion of Airbnb and similar platforms. In fact, the decline in the number of households and the population has been constant since 2011-the period that marked the affirmation of the Airbnb phenomenon in the city. Tenants are especially affected as landlords replace them with visitors, and this seems to be particularly relevant in the Gòtic area as the percentage of homeowners is only $27.4 \%$, whereas the average in Barcelona is $58.9 \%$. For instance, a landlord stated

I inherited the building from my mother in 2009. I have five flats there. The agreements with tenants expired in 2010-2011, so for me it was easy to get rid of them.

Interviews with transnational migrants reveal that they are young professionals and suggest that tourism is a central explanatory variable in understanding why they settled in the Gòtic area rather than in other neighbourhoods, confirming the spatial overlap of tourism and other forms of mobilities (Novy, 2018). Most participants mentioned the feeling of integration and satisfaction that they experience in the area because they can maintain a leisure-led lifestyle and have transnational friends, whereas other less central neighbourhoods are 'more Spanish'. For instance, when asked why he moved to the Gòtic area, a North American resident explained that he feels more comfortable there because he finds services in English and is surrounded 'by people like me'. Tourism in the Gòtic area has caused a growth in the number of cafes, restaurants and self-styled 'tapas' bars catering to transnational consumers that in fact have little to do with traditional Spanish food and culture. In such places, the staff speak English and serve 'brunch' alongside other gastronomic specialities according to globalised standards of consumption (Soro, 2016). Interestingly, from the point of view of long-term Spanish residents, the fact that migrants become spatially concentrated in tourist enclaves implies the formation of transnational commercial and residential spaces, and this seems to be crucial in explaining why Spanish people have been moving out of the neighbourhood. An opinion repeated among Spanish participants is that 'bars sell things that are not for us' and that 'the feeling is that you do not have places to go to'.

The transient nature of the populations attracted into the neighbourhood, whether the 'tsunami of visitors', as one resident put it, or the transnational dwellers such as international students or cosmopolitan professionals, is a key driver of distress for the long-term resident population. All participants mentioned that although there is little chance of meaningful encounters with hurried visitors, the floating population of transnational dwellers is also leaving little space for establishing neighbourly interactions. In fact, many Spanish residents define the flow of young transnational gentrifiers as 'permanent tourists'. This seems to be eroding a sense of community based on social relations, which long-term residents consider essential to reproduce their quality of life. For instance, a primary school teacher who has been working in the area for 30 years notes that 'European children are mobile like their parents. It is not the norm that they start school and finish it six years later', or as a Spanish resident states: 'The apartments are occupied, but they are not occupied by neighbours. A distinction must be made between the more permanent people and the ones who are passing through'. Similarly, 'It is very difficult to live in a community where there are no permanent neighbours'. As a result of this transformation of the neighbourhood's social configuration, long-term Spanish residents see the support and care that stable social networks provide progressively eroded and feel increasingly isolated and helpless. Notably, such loss of community relations affects the elderly the most as well as the neighbours-mainly women-who look after them:

Living with neighbours is not the same as living with transient people. My dad is 82. I was not worried too much because I knew I had Eva [his next-door neighbour]. But now he does not have her anymore. In the building there are tourists and newcomers from Europe. Probably they are nice people, but my dad does not feel he is accompanied in the neighbourhood. That mutual help is crucial. The elderly who are left without a familiar environment, without a neighbour (...): it is the rupturing of social bonds.

\section{5 | DISCUSSION AND CONCLUSIONS: GENTRIFICATION IN THE AGE OF MOBILITIES}

Smith (2002) suggested that the 'end result' of any example of gentrification is a process of population restructuring and residential mobility, manifested in the profiles of the in-movers and out-movers. Yet, despite the rise of research on tourism-led gentrification, the evidence to suggest what it looks like in terms of population dynamics is scarce. Our analysis of the transformation of the socio-demographic structure of the Barri Gòtic since the late 1990s allows us to identify this empirical gap. In these conclusions, we draw from the conceptual and 
epistemological toolbox of the 'mobilities paradigm' to offer an original interpretation of our results, which point to a specific form of gentrification, but based on different processes and possibly a wider ontology of forces at play than in classical gentrification.

The mobilities literature invites us to examine space as constructed and constantly reproduced in its material, social and semantic dimensions through the practices, negotiations and interrelations of a myriad of human and nonhuman mobilities (Cresswell \& Merriman, 2011). Cresswell (2010) and Kaufmann, Bergman, and Joye (2004), among others, postulate a political dimension of mobility, the product of a multitude of human/environment interfaces (Cresswell, 2006, p. 167), suggesting that the distribution of power in the negotiation for/through space can be analysed through the uneven characteristics of the mobilities involved and their relational codetermination; as argued by Adey (2010), 'mobility and immobility are understood as an effect or an outcome of a relation-of a position or of effort and pressure' (p. 18). In this sense, it can be proposed that both tourist and nontourist mobilities are involved in the production and distribution of power unfolding in gentrification processes and that these mobilities 'are both productive of such social relations and produced by them' (Cresswell, 2010, p. 21).

This analytic approach unfolds in two dimensions in our paper, firstly, in terms of the supposed opposition between stable and transient populations, namely, residents versus visitors. This point is important to challenge the rebuke of touristification as a form of gentrification (e.g., in Jover \& Díaz-Parra, 2019, p. 7: 'Touristification (...) cannot be strictly understood as gentrification because the tourists do not settle down permanently'). The resident versus visitor dichotomy seems to be a simplification of a process of population restructuring that may be better understood as the result of flows of different forms of tourism mobilities. We showed how a tourist neighbourhood is attractive for flows of young transnational people with different levels of transitory character, from the short stay of visitors, the longer stay of students and the similarly transitory settlement of young professionals. In this sense, we claim that tourism gentrifies-driving processes of place restructuring that make such areas rather attractive for an array of transnational gentrifiers, which seem to intensify the traditional reading of gentrification as a transitory place of dwelling in the life course of young middle-class populations. From a methodological viewpoint, we propose that the analysis of mobility-related indicators hinting at the mobile biographies of gentrifiers suggested in this paper may be a fundamental addition to current readings of gentrification.

Secondly, the mobility perspective also unfolds in terms of the distribution of power and the material dimensions of the negotiation for dwellings, and ultimately for space, that a performative reading of the 'mobilities clash' in touristified neighbourhood presupposes. Such negotiation is exclusively based not only on economic power but also on other factors, as underlined by Cresswell (2010), such as physical prowess, available time, or cognitive capacity. From this point of view, we clarify that although class differences still underpin the gentrification of the Gòtic neighbourhood, there are material dimensions at play-the uneasiness of long-term, less educated and less adaptive long-terms residents in 'sharing space' with mobile populations, and conversely the convergence between the mobile and dwelling practices of transnational gentrifiers and tourists-which mark a fundamental trait of tourism-driven gentrification. We have shown that the neighbourhood loses portions of its resident population, as a sizeable part of the housing stock is occupied by 'mobile dwellers' that stay for short to medium periods of time and lay down barely any roots in the community. At the same time, the analysis of migration flows reveals that transnational gentrifiers tend to dwell in the Gòtic as part of a transitory period. The tourist transformation of the neighbourhood, distressful as it may be for long-term Spanish residents, seems in fact to be a pull factor for young transnational populations. They could thus be characterised as a mobile and floating population as well, in between the stickier, sedentary character of long-term residents and the extremely short nature of visitors' transits. The point is that although the residential base of the Gòtic has not completely receded, the increasing substitution of long-term residents with transient dwellers is key to understanding the impacts of this process on community life. As revealed by our interviews, the overcrowding of public space, the noise at night time and the reorientation of the commercial structure to meet the demand of such groups are all affecting the everyday life of elderly and long-term residents, especially when the social ties and support system that 'stable' community networks provide are also receding. If they do not leave the area for purely economic reasons, they may well decide to do so in search of a better quality of life in other neighbourhoods. This does have peculiar consequences in terms of the area dynamics, such as the erosion of a taxpayer base, democratic representation and resident-oriented commercial and social services that are necessary to support the lives of long-term individuals who stay in the neighbourhood.

Thus, some key characteristics of tourist mobilities-for instance, their temporal and compressed patterns, their dependency on systems of signs (and increasingly on technologies) that decipher place and allow an easy anchoring to it or their relatively loose rhythms in terms of day/night-time routines-exacerbate their competitive capacity over urban assets. On the one hand, these characteristics are not at odds with the spatial and social dwelling practices of some transnational hypermobile populations, who are indeed attracted to dwelling in 'touristy' areas. On the other hand, this assemblage of transient mobilities unsettles the position of 'stickier' and more dependent resident populations in the negotiation over 'moorings' (Hannam et al., 2006), such as housing, commercial structures and other forms of social capital, ultimately provoking their abandonment from neighbourhoods of high tourist intensity. Eventually, a local and 'sedentary' resident population is replaced by transient dwellers, a floating transnational middle-class population that is extremely adaptive, especially in regard to practices of habitation (changing home frequently, renting with short-term contracts, subletting rooms to allow them to stay in expensive city centre locations, sharing home among fellow students or single expats, etc.).

In conclusion, tourism does drive gentrification but a particular form of gentrification that may be better explained by considering a mobilities perspective, in which class determinants are as important as 
negotiation in motion-that is, power enacted by actual mobility, representations of mobility and embodiments of mobility (Jensen, 2010). Future research could be useful to unpack different aspects of this 'silent struggle' examining closely the hindrances that 'living with tourists' produces for long-term residents or assessing the role that housing and area renewal policies may have in moderating this pressure.

\section{ACKNOWLEDGEMENTS}

We would like to thank the editors of the journal and the two anonymous reviewers for their constructive feedback. We are also extremely grateful to the personnel of the Department of Statistics of the Barcelona City Council for their constant support providing sociodemographic data.

\section{CONFLICT OF INTEREST}

The authors declare that they have not conflict of interest.

\section{FUNDING INFORMATION}

This research received financial support from Talent Program (Universitat Autònoma de Barcelona); Spanish Ministry of Science and Innovation, GLOBFAM (RTI2018-096730-B-I00), MOVIPOL (CSO2014-60967-JIN) and POLITUR (CSO2017-82156-R and AEI/ERDF-EU) projects; Department of Research and Universities (2017SGR22) and Programa Cerca of the Catalan Government; the Portuguese Science and Technology Research Council (FCT) within the scope of the SMARTOUR project (Ref: PTDC/GESURB/30551/2017) and the projects UIDB/00295/2020 and UIDP/00295/2020; European Research Council, EQUALIZED project (ERC-2014-STG-637768).

\section{ORCID}

Antonio López-Gay (D) https://orcid.org/0000-0001-8892-2816

Agustin Cocola-Gant (D) https://orcid.org/0000-0003-3395-4233 Antonio Paolo Russo (D) https://orcid.org/0000-0001-8768-246X

\section{REFERENCES}

Adey, P. (2010). Mobility, Key ideas in Geography. London: Routledge.

Ajuntament de Barcelona. (1999). La població de Ciutat Vella. Barcelona Societat, 9, 5-13.

Ap, J., \& Crompton, J. L. (1993). Residents' strategies for responding to tourism impacts. Journal of Travel Research, 32(1), 47-50. https://doi. org/10.1177/004728759303200108

Arbaci, S., \& Tapada-Berteli, T. (2012). Social inequality and urban regeneration in Barcelona city centre: Reconsidering success. European Urban and Regional Studies, 19(3), 287-311. https://doi.org/10.1177/ 0969776412441110

Atkinson, R. (2000). Measuring gentrification and displacement in Greater London. Urban Studies, 37(1), 149-165. https://doi.org/10.1080/ 0042098002339

Bailey, N., \& Robertson, D. (1997). Housing renewal, urban policy and gentrification. Urban Studies, 34(4), 561-578. https://doi.org/10. 1080/0042098975925

Balibrea, M. P. (2001). Urbanism, culture and the post-industrial city: Challenging the 'Barcelona model'. Journal of Spanish Cultural Studies, 2(2), 187-210. https://doi.org/10.1080/14636200120085174
Barcelona City Council. ; Barcelona Provincial Council. ; Barcelona Tourism Consortium. (2017). Tourism statistics. Barcelona: City and region. Retrieved from https://ajuntament.barcelona.cat/turisme/sites/ default/files/documents/171907_estadistiques_curt_2016_ultima_ versio.pdf

Bayona, J. (2006). Factors sociodemogràfics de la distribució espacial de la població de nacionalitat estrangera a Barcelona (Unpublished doctoral dissertation). Barcelona: Universitat Autònoma de Barcelona.

Becker, E. (2015). The revolt against tourism. New York Times 17.7.2015. Retrieved from. https://www.nytimes.com/2015/07/19/opinion/ sunday/the-revolt-against-tourism.html?_r=0

Benson, M., \& O'Reilly, K. (2009). Migration and the search for a better way of life: A critical exploration of lifestyle migration. The Sociological Review, 57(4), 608-625. https://doi.org/10.1111/j.1467-954X.2009. 01864.x

Bianchi, R. V. (2020). COVID-19 and the potential for a radical transformation of tourism? ATLAS Tourism and Leisure Review, 2020(2), 80-86.

Boyle, M., \& Hughes, G. (1991). The politics of the representation of 'the real': Discourses from the Left on Glasgow's role as European City of Culture, 1990. Area, 23(3), 217-228.

Brandajs, F., \& Russo, A. P. (2019). Whose is that square? Cruise tourists' mobilities and negotiation for public space in Barcelona. Applied Mobilities, 1-25. https://doi.org/10.1080/23800127.2019.1576257

Butler, R. W., \& Dodds, R. (Eds.) (2019). Overtourism: Issues, realities and solutions (Vol. 1). Oldenburg: De Gruyter.

Carvalho, L., Chamusca, P., Fernandes, J., \& Pinto, J. (2019). Gentrification in Porto: floating city users and internationally-driven urban change. Urban Geography, 40(4), 565-572. https://doi.org/10.1080/ 02723638.2019.1585139

Celata, F., \& Romano, A. (2020). Overtourism and online short-term rental platforms in Italian cities. Journal of Sustainable Tourism, 1-20. https:// doi.org/10.1080/09669582.2020.1788568

Cocola-Gant, A. (2016). Holiday rentals: The new gentrification battlefront. Sociological Research Online, 21(3), 10-120. https://doi.org/10.5153/ sro.4071

Cocola-Gant, A. (2018). Tourism gentrification. In L. Lees \& M. Phillips (Eds.), Handbook of gentrification studies (pp. 281-293). Cheltenham and Northampton: Edward Elgar Publishing. DOI: https://doi.org/10. 4337/9781785361746.00028

Cocola-Gant, A., \& Gago, A. (2019). Airbnb, buy-to-let investment and tourism-driven displacement. A case study in Lisbon. Environment and Planning A: Economy and Space, 1-18. https://doi.org/10.1177/ $0308518 \times 19869012$

Cocola-Gant, A., \& Lopez-Gay, A. (2020). Transnational gentrification, tourism and the formation of 'foreign only' enclaves in Barcelona. Urban Studies, 1-19. https://doi.org/10.1177/0042098020916111

Colomb, C., \& Novy, J. (2016). Urban tourism and its discontents: An introduction. In C. Colomb \& J. Novy (Eds.), Protest and resistance in the Tourist City (pp. 1-30). London: Routledge. https://doi.org/10. 4324/9781315719306

Cresswell, T. (2006). On the move: Mobility in the modern western world. London: Routledge.

Cresswell, T. (2010). Towards a politics of mobility. Environment and Planning D: Society and Space, 28(1), 17-31. https://doi.org/10.1068/ d11407

Cresswell, T., \& Merriman, P. (Eds.) (2011). Geographies of mobilities: Practices, spaces, subjects. Surrey: Ashgate Publishing Ltd.

Eisinger, P. (2000). The politics of bread and circuses: Building the city for the visitor class. Urban Affairs Review, 35(3), 316-333. https://doi.org/ 10.1177/107808740003500302

Evans, G. (2009). From cultural quarters to creative clusters: Creative spaces in the new city economy. In M. Legner (Ed.), The sustainability and development of cultural quarters: International perspectives (p. 32.59). Stockholm: Institute of Urban History. 
Ford, T., \& Champion, T. (2000). Who moves into, out of and within London? Area, 32(3), 259-270. https://doi.org/10.1111/j.1475-4762. 2000.tb00139.x

García-Hernández, M., la Calle-Vaquero, D., \& Yubero, C. (2017). Cultural heritage and urban tourism: Historic city centres under pressure. Sustainability, 9(8). https://doi.org/10.3390/su9081346

García-Herrera, L. M., Smith, N., \& Mejías-Vera, M. A. (2007). Gentrification, displacement, and tourism in Santa Cruz de Tenerife. Urban Geography, 28(3), 276-298. https://doi.org/10.2747/02723638.28.3.276

Gotham, K. F. (2005). Tourism gentrification: The case of New Orleans' vieux carré (French Quarter). Urban Studies, 42(7), 1099-1121. https://doi.org/10.1080/00420980500120881

Gravari-Barbas, M., \& Guinand, S. (2017). Introduction: Addressing tourism-gentrification processes in contemporary metropolises. In M. Gravari-Barbas \& S. Guinand (Eds.), Tourism and gentrification in contemporary metropolises (pp. 1-21). London: Routledge. DOI: https://doi.org/10.4324/9781315629759-1

Hall, C. M. (2013). Regeneration and cultural quarters: Changing urban cultural space. In M. Smith \& G. Richards (Eds.), The Routledge handbook of cultural tourism (pp. 332-338). London: Routledge.

Hall, C. M., Scott, D., \& Gössling, S. (2020). Pandemics, transformations and tourism: Be careful what you wish for. Tourism Geographies., 22, 577-598. https://doi.org/10.1080/14616688.2020.1759131

Hannam, K., Sheller, M., \& Urry, J. (2006). Mobilities, immobilities and moorings. Mobilities, 1(1), 1-22. https://doi.org/10.1080/ 17450100500489189

Hayes, M. (2018). Gringolandia: Lifestyle Migration under Late capitalism. Minneapolis: University of Minnesota Press. https://doi.org/10.5749/ j.ctv6q52rv

Haywood, K. M. (2020). A post-COVID future: Tourism community reimagined and enabled. Tourism Geographies, 22, 599-609. https://doi. org/10.1080/14616688.2020.1762120

Hochstenbach, C., \& Boterman, W. (2018). Age, life course and generations in gentrification processes. In L. Lees \& M. Phillips (Eds.), Handbook of gentrification studies (pp. 170-185). Cheltenham and Northampton: Edward Elgar Publishing. DOI: https://doi.org/10. 4337/9781785361746.00021

Hochstenbach, C., Musterd, S., \& Teernstra, A. (2015). Gentrification in Amsterdam: Assessing the importance of context. Population, Space and Place, 21(8), 754-770. https://doi.org/10.1002/psp.1854

Hochstenbach, C., \& van Gent, W. P. (2015). An anatomy of gentrification processes: Variegating causes of neighbourhood change. Environment and Planning a: Economy and Space, 47(7), 1480-1501. https://doi. org/10.1177/0308518X15595771

Huete, R., \& Mantecón, A. (2011). Residential tourism or lifestyle migration: Social problems linked to the non-definition of the situation. In O. Moufakkir \& M. P. Burns (Eds.), Controversies in tourism (pp. 160-171). Wallingford: $C A B$ International.

Janoschka, M., Sequera, J., \& Salinas, L. (2014). Gentrification in Spain and Latin America-A critical dialogue. International Journal of Urban and Regional Research, 38(4), 1234-1265. https://doi.org/10.1111/14682427.12030

Jansen-Verbeke, M. (1998). Tourismification of historical cities. Annals of Tourism Research, 25(3), 739-742. https://doi.org/10.1016/S01607383(98)00015-2

Jensen, O. B. (2010). Negotiation in motion: Unpacking a geography of mobility. Space and Culture, 13(4), 389-402. https://doi.org/10.1177/ 1206331210374149

Jover, J., \& Díaz-Parra, I. (2019). Gentrification, transnational gentrification and touristification in Seville, Spain. Urban Studies. https://doi.org/10. 1177/0042098019857585

Judd, D. R., \& Fainstein, S. S. (Eds.) (1999). The tourist city. New Haven, CT: Yale University Press.
Kaufmann, V., Bergman, M. M., \& Joye, D. (2004). Motility: Mobility as capital. International Journal of Urban and Regional Research, 28(4), 745-756. https://doi.org/10.1111/j.0309-1317.2004.00549.x

King, R. (2018). Theorising new European youth mobilities. Population, Space and Place, 24, e2117. https://doi.org/10.1002/psp.2117

Koens, K., Postma, A., \& Papp, B. (2018). Is overtourism overused? Understanding the impact of tourism in a city context. Sustainability, 10(12). https://doi.org/10.3390/su10124384

Law, C. (2002). Urban tourism: the visitor economy and the growth of large cities. London: Continuum.

Lees, L., Slater, T., \& Wyly, E. (2008). Gentrification. London and New York: Routledge.

López-Gay, A. (2008). Canvis residencials i moviments migratoris en la renovació poblacional de Barcelona. Barcelona: CTESC.

López-Gay, A. (2016). Barcelona's got talent: migration, residential change and socioeconomic polarisation. Perspectives Demogràfiques, 3.

Maitland, R., \& Newman, P. (2008). Visitor-host relationships: conviviality between visitors and host communities. In B. Hayllar, T. Griffin, \& D. Edwards (Eds.), City spaces, tourist places: Urban tourism precincts (pp. 223-242). Oxford: Butterworth-Heinemann. DOI: https://doi. org/10.1016/B978-0-7506-8195-7.00011-1

Malet-Calvo, D. (2018). Understanding international students beyond studentification: A new class of transnational urban consumers. The example of Erasmus students in Lisbon (Portugal). Urban Studies, 55(10), 2142-2158. https://doi.org/10.1177/004209801 7708089

Mendes, L. (2018). Tourism gentrification in Lisbon. The panacea of touristification as a scenario of post-capitalist crisis. In I. David (Ed.), Crisis, austerity and transformation: How disciplining neoliberalism is changing Portugal (pp. 25-46). London: Lexington.

Milano, C., Cheer, J., \& Novelli, M. (Eds.) (2019). Overtourism: Excesses, discontents and measures in travel and tourism. Wallingford: CABI. DOI: https://doi.org/10.1079/9781786399823.0000

Montezuma, J., \& McGarrigle, J. (2019). What motivates international homebuyers? Investor to lifestyle 'migrants' in a tourist city. Tourism Geographies, 21(2), 214-234. https://doi.org/10.1080/14616688. 2018.1470196

Nofre, J., Giordano, E., Eldridge, A., Martins, J. C., \& Sequera, J. (2018). Tourism, nightlife and planning: Challenges and opportunities for community liveability in La Barceloneta. Tourism Geographies, 20(3), 377-396. https://doi.org/10.1080/14616688.2017.1375972

Novy, J. (2018). 'Destination' Berlin revisited. From (new) tourism towards a pentagon of mobility and place consumption. Tourism Geographies, 20(3), 418-442. https://doi.org/10.1080/14616688.2017. 1357142

Ogden, P. E., \& Hall, R. (2004). The second demographic transition, new household forms and the urban population of France during the 1990s. Transactions of the Institute of British Geographers, 29, 88-105. https://doi.org/10.1111/j.0020-2754.2004.00116.x

Ogden, P. E., \& Schnoebelen, F. (2005). The rise of the small household: Demographic change and household structure in Paris. Population, Space and Place, 11, 251-268. https://doi.org/10.1002/psp.370

Pappalepore, I., Maitland, R., \& Smith, A. (2010). Exploring urban creativity: Visitor experiences of Spitalfields, London. Tourism Culture \& Communication, 10(3), 217-230. https://doi.org/10.3727/ $109830410 \times 12910355180946$

Pinkster, F., \& Boterman, W. (2017). When the spell is broken: Gentrification, urban tourism and privileged discontent in the Amsterdam canal district. Cultural Geographies, 24(3), 457-472. https://doi.org/10. 1177/1474474017706176

Porcel, S. (2016). Dinámicas de estructuración socioresidencial en la Barcelona metropolitana postindustrial ¿Hacia una ciudad dual o cuarteada? (Unpublished doctoral dissertation). Barcelona: Universitat Autònoma de Barcelona. 
Quinn, B. (2007). Performing tourism Venetian residents in focus. Annals of Tourism Research, 34(2), 458-476. https://doi.org/10.1016/j.annals. 2006.11.002

Reese, E., DeVerteuil, G., \& Thach, L. (2010). 'Weak-Center' gentrification and the contradictions of containment: Deconcentrating poverty in downtown Los Angeles. International Journal of Urban and Regional Research, 34(2), 310-327. https://doi.org/10.1111/j.1468-2427.2010. 00900.x

Russo, A. P., \& Capel Tatjer, L. (2007). From citadels of education to Cartier Latins (and back?): The changing landscapes of student populations in European cities. Geography Compass, 1(5), 1160-1189. https://doi. org/10.1111/j.1749-8198.2007.00056.x

Russo, A. P., \& Scarnato, A. (2018). 'Barcelona in Common': A new urban regime for the 21st century tourist city? Journal of Urban Affairs, 40(4), 455-474. https://doi.org/10.1080/07352166.2017.1373023

Russo, A. P., \& Van der Borg, J. (2010). An urban policy framework for culture-oriented economic development: Lessons from the Netherlands. Urban Geography, 31(5), 668-690. https://doi.org/10. 2747/0272-3638.31.5.668

Sales, J. (2019). Especialització turística, gentrificació i dinàmiques residencials en un entorn urbà madur, el cas de Barcelona. (Unpublished doctoral dissertation). Barcelona: Universitat Autònoma de Barcelona.

Sequera, J., \& Nofre, J. (2018). Shaken, not stirred: New debates on touristification and the limits of gentrification. City, 22(5-6), 843-855. https://doi.org/10.1080/13604813.2018.1548819

Sequera, J., \& Nofre, J. (2019). Touristification, transnational gentrification and urban change in Lisbon: The neighbourhood of Alfama. Urban Studies. https://doi.org/10.1177/0042098019883734

Sheller, M., \& Urry, J. (2004). Tourism mobilities: Places to play, places in play. London: Routledge.

Sheller, M., \& Urry, J. (2006). The new mobilities paradigm. Environment and Planning $a$, 38(2), 207-226. https://doi.org/10.1068/a37268

Sigler, T., \& Wachsmuth, D. (2016). Transnational gentrification: Globalisation and neighbourhood change in Panama's Casco Antiguo. Urban Studies, 53(4), 705-722. https://doi.org/10.1177/ 0042098014568070

Slater, T. (2009). Missing Marcuse: On gentrification and displacement. City, 13(2-3), 292-311. https://doi.org/10.1080/13604810902 982250

Smith, A. (2005). Conceptualizing city image change: The 're-imaging' of Barcelona. Tourism Geographies, 7(4), 398-423. https://doi.org/10. 1080/14616680500291188

Smith, D. P. (2002). Extending the temporal and spatial limits of gentrification: A research agenda for population geographers. International
Journal of Population Geography, 8(6), 385-394. https://doi.org/10. 1002/ijpg.267

Soro, E. (2016). Between translation and reinterpretation: What is local in Barcelona's foodsphere? In A. P. Russo \& G. Richards (Eds.), Reinventing the local in tourism: Producing, consuming and negotiating place (pp. 185-208). Clevedon: Channel View. DOI: https://doi.org/10. 21832/9781845415709-014

Terhorst, P., Ven, J., \& Deben, L. (2003). Amsterdam: It's all in the mix. In L. Hoffman, S. Fainstein, \& D. R. Judd (Eds.), Cities and visitors: Regulating people, markets, and city space (pp. 75-90). Oxford: Blackwell. DOI: https://doi.org/10.1002/9780470773673.ch4

Tironi, M. (2009). The paradoxes of cultural regeneration: Artists, neighbourhood redevelopment and the 'creative city' in Poblenou, Barcelona. Journal of Urban Regeneration \& Renewal, 3(1), 92-105.

Urry, J. (2000). Sociology beyond societies: Mobilities for the twenty-first century. London: Routledge.

Van Criekingen, M. (2010). 'Gentrifying the re-urbanisation debate', not vice versa: The uneven socio-spatial implications of changing transitions to adulthood in Brussels. Population, Space and Place, 16(5), 381-394. https://doi.org/10.1002/psp.582

Wachsmuth, D., \& Weisler, A. (2018). Airbnb and the rent gap: Gentrification through the sharing economy. Environment and Planning $a$ : Economy and Space, 50(6), 1147-1170. https://doi.org/10.1177/ $0308518 \times 18778038$

Williams, A. M., \& Hall, C. M. (2000). Tourism and migration: New relationships between production and consumption. Tourism Geographies, 2(1), 5-27. https://doi.org/10.1080/146166800363420

Yrigoy, I. (2019). Rent gap reloaded: Airbnb and the shift from residential to touristic rental housing in the Palma Old Quarter in Mallorca, Spain. Urban Studies, 56(13), 2709-2726. https://doi.org/10.1177/ 0042098018803261

Zanardi, C. (2019). Complexity-cage. Toward a critical deconstruction of "tourism-phobia". The Urban Transcripts Journal, 2(1). Retrieved from http://journal.urbantranscripts.org/article/complexity-cage-towardcritical-deconstruction-tourism-phobia-clara-zanardi/

How to cite this article: López-Gay A, Cocola-Gant A, Russo AP. Urban tourism and population change: Gentrification in the age of mobilities. Popul Space Place. 2020; e2380. https://doi.org/10.1002/psp.2380 